\title{
Use of Antipsychotics: A Study from the French National Insurance Healthcare System Database
}

\author{
Gaëlle Désaméricq 1,2,3,4, Franck Schürhoff',5,6, Isabelle Macquin-Mavier,3, \\ Anne-Catherine Bachoud-Lévi1 ${ }^{1,2,3,4}$, Patrick Maison ${ }^{8}$ \\ ${ }^{1}$ Département d’Etudes Cognitives, Ecole Normale Supérieure, Paris, France \\ ${ }^{2}$ Inserm, U955, Equipe 01, Créteil, France \\ ${ }^{3}$ Faculté de médecine, Université Paris Est, Créteil, France \\ ${ }^{4}$ Centre de Référence Maladie de Huntington, AP-HP, Hôpital H. Mondor-A. Chenevier, Créteil, France \\ ${ }^{5}$ Inserm, U955, Equipe 15, Créteil, France \\ ${ }^{6}$ Pôle de Psychiatrie, AP-HP, Hôpital H. Mondor-A. Chenevier, Créteil, France \\ ${ }^{7}$ Pharmacologie Clinique, AP-HP, Hôpital H. Mondor-A. Chenevier, Créteil, France \\ ${ }^{8}$ Ansm, Surveillance Division, Saint Denis, France \\ Email: patrickmaison1@gmail.com
}

Received 1 July 2015; accepted 23 August 2015; published 26 August 2015

Copyright (C) 2015 by authors and Scientific Research Publishing Inc.

This work is licensed under the Creative Commons Attribution International License (CC BY).

http://creativecommons.org/licenses/by/4.0/

c) (i) Open Access

\section{Abstract}

A marked increase in antipsychotic prescriptions has been observed in most countries since the introduction of second-generation antipsychotics. Misuse could partly explain this rise. We described the use of antipsychotic medication in France. This retrospective analysis was conducted on the sample "Echantillon généraliste de beneficiaries" from the French National Insurance Healthcare System. All reimbursements for antipsychotic medications in 2010 were identified. Antipsychotics use was described in terms of patient's profiles and condition of use. In 2010, we identified 11,729 single patients with at least one reimbursement for antipsychotic medication (2.23\% of French health insurance beneficiaries). The mean age in the population was 54 (sd 20) years. Forty-one percent had declared psychiatric disorder and $15 \%$ had a psychiatric follow-up for unknown diseases. Schizophrenia, others psychosis and personality disorders were the three main diagnoses of psychiatric disease. Patients without declared psychiatric disorders and without psychiatric follow-up accounted for $23 \%$ (aged between 15 and 65 ) and 20\% (aged 65 years and over) of the population using antipsychotics. Forty-five percent of patients aged between 15 and 65 had more than 3 months of treatment refunded. Patients aged 65 years and over were $69 \%$ without dementia and $47 \%$ had more than three months of treatment of antipsychotics refunded during the year. These results suggested that antipsychotic treatments were used in France at long term in particular for patients without declared psychiatric disorder or psychiatric follow-up. 


\section{Keywords}

\section{Antipsychotics, Outpatients, Pharmaco-Epidemiology, Database, France, Use}

\section{Introduction}

Antipsychotics have been marketed since the 1950s. Antipsychotics are broadly divided into two groups: the first generation and the second generation, much more recent. There are four first generation antipsychotic classes: phenothiazines (tricyclic ring), butyrophenones (benzene ring bonded to an atom of iron and a chain that may include cycles), thioxanthenes (related to phenothiazine but the nitrogen atom is replaced by a carbon atom) and benzamides. Second generation antipsychotics fall into the following classes: dibenzoazepines (structural relationship with imipramine), dibenzodiazepines (tricyclic structure similar to that of phenothiazines), benzisoxazoles, imidazolidinone and quinolinone. All antipsychotics act by blocking dopamine receptors, particular subtype postsynaptic D2. Antipsychotic medication is indicated for treating acute and chronic psychotic disorders, mood disorders such as bipolar disorders or behavioral disorders. Antipsychotics, allowing treatment of acute phase and relapse prevention, must be maintained in the long term in case of psychotic and mood disorders while patients with behavioral disorders such as agitation during acute or chronic psychotic conditions, persistent aggression in patients with dementia or patients with chronic alcoholism, anxiety, used antipsychotics for short term treatment [1]. Considering the off-label use, sleep disorders or anxiety, for example, are not mentioned in their Summary of Product Characteristics. The concerns of antipsychotic use include possible adverse effects (including weight gain, diabetes mellitus, tardive dyskinesia, and extrapyramidal symptoms) and excessive mortality in the elderly [2] [3].

Nevertheless, a progressive increase in antipsychotic prescriptions has been observed in most countries since the introduction of second-generation antipsychotic (SGAPs) [4]. Due to their better neurologic tolerance, the use of these antipsychotics leads to several off-label uses; however, there is evidence of the efficacy of atypical antipsychotic medications for only a few of the off-label conditions that are currently being treated [5]. In addition to concerns about efficacy and safety, the off-label use and the misuse have an economic effect on the health care system. In USA, the estimated cost associated with off-label use of antipsychotics was US \$6.0 billion in 2008 [6]. Besides the use of antipsychotics for purposes for which it was not intended, another misuse of antipsychotics was found i.e., long-term use of antipsychotics in seniors who had recorded dementia [7].

The representative sample extracted from the French national database of health insurance allows describing the use of antipsychotic medication in France.

\section{Materials and methods}

\subsection{Sources of Data}

A cross-sectional study was carried out using a sample extracted from the French National Insurance Healthcare System database called "Echantillon généraliste de bénéficiaires" (EGB). The EGB is based on a survey at the 97th percentile on the social security (national health insurance) number of French health insurance beneficiaries, whether they have received healthcare reimbursements or not [8]. Over 500,000 people are currently registered, representative of the population (excluding public service employees and students). It contains anonymous information on the socio-demographic and medical characteristics of beneficiaries, the specialty of the prescriber and date and the drug motivating the reimbursement.

\subsection{Measurements}

Antipsychotic medication was identified according to the Anatomical Therapeutic Chemical [ATC] Classification System code N05A that also include lithium. Antipsychotic medications were classified into second-generation antipsychotics (clozapine, olanzapine, amisulpride, tiapride, risperidone and aripiprazole), first-generation antipsychotics (other antipsychotics) and lithium. Products containing veralipride used to treat hot flushes were withdrawn from the market in 2007 and were excluded from the analyses. A number of antipsychotic refunds were extracted for each patient. Anticholinergic, hypnotic, antidepressant, anxiolytic medication were also iden- 
tified for each patient. Patient characteristics (age, sex), comorbidities (dementia, psychiatric disorders) and psychiatric/general practitioner examinations and prescriptions were extracted. Chronic diseases may be eligible for "ALD" ("Affection de longue durée"), i.e. reimbursed 100\% when the disease is declared to the healthcare insurance system, and this field is coded according to ICD-10 (10th version of International Classification of Diseases). Comorbid diagnoses included dementia (ICD-10: F00-F09, G30 and/or at least one claim for drugs: N06D), schizophrenia (ICD-10: F20-F21,F25), bipolar disorder (ICD-10: F31), anxiety disorder (ICD-10: F40-F42), depression (ICD-10: F32-F34), other psychosis (ICD-10: F22-F23, F28-F29, F44), personality disorders (ICD-10: F60), mental retardation (ICD-10: F70-F79), alcohol abuse (ICD-10: F10), pervasive developmental disorders (ICD-10: F84).

\subsection{Analysis}

First, the proportion of patients with at least one reimbursement from 2006 to 2010 was determined for each year. Second, the characteristics of patients and antipsychotic treatment were described. According to the European Medicine Agency, misuse refers to situations where the medicinal product is intentionally and inappropriately used not in accordance with the authorized product information [9]. All psychiatric diseases allowing long term treatment according to the authorized information of the antipsychotics drugs are listed in the ALD list of the French health insurance system. Patients without an ALD for psychiatric disorder and without a follow-up by a psychiatrist (at least one visit to a community psychiatrist) and who used an antipsychotic for at least four months (at least 4 refunds) during the year were considered to have received these medications inappropriately (misuse). To minimize misuse patients with psychiatric follow-up but without ALD were considered as having psychiatric disease allowing long term treatment according to the authorized information of the antipsychotic drugs but not yet registered in the health insurance system.

To quantify the observance in the psychiatric group the Cumulative Mean Gap has been assessed. The ratio is the total days of treatment gaps divided by the total days to next fill or end of observation period [10]. The extraction and use of data were carried out with the SAS software, version 9.1.

\section{Results}

\subsection{Trends in Antipsychotic Use}

The total prevalence of patients with at least one reimbursement for antipsychotic treatment remained stable between 2006 and 2010 (Figure 1), with a decrease of First-Generation Antipsychotics (FGAPs) and an increase of SGAPs during the 5-years period until a same level of use.

We identified 11,729 single patients with at least one reimbursement for an antipsychotic medication in 2010 corresponding to $2.23 \%$ of French health insurance beneficiaries. The mean age in the population was 54 years (sd 20) and 53\% were women. Antipsychotics reimbursement occurred in $0.21 \%$ of patients younger than 15

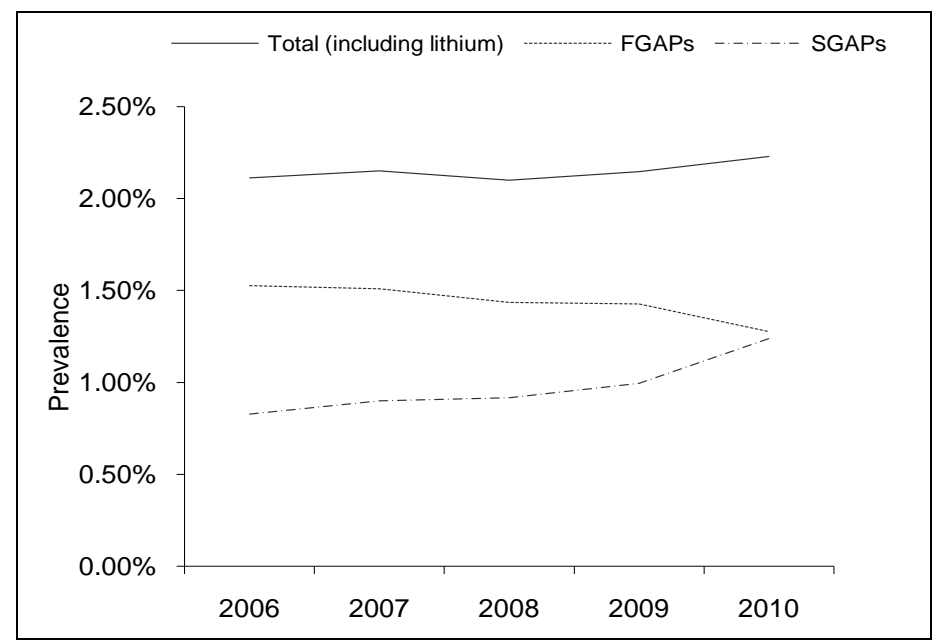

Figure 1. Prevalence of patients with at least one reimbursement of antipsychotic between 2006 and 2010. 
years old and in $4.36 \%$ of patients older than 65 years old.

In 2010, cyamemazine was the most commonly reimbursed antipsychotic drug (27.0\% of the patients) (Table 1). The SGAPs, risperidone (22.6\%) and olanzapine (13.7\%), were also commonly reimbursed. Patients taking haloperidol represented $10 \%$ of our population and they were more prone to use anticholinergic (41\%). Characteristics of patients treated with FGAPs and SGAPs did not differ.

\subsection{Patients with an ALD for Long-Term Psychiatric Disorder or with Psychiatric Follow-Up}

$41 \%$ of patients had long-term psychiatric disorder according to ALD (10\% schizophrenia, 6\% bipolar disorder and $9 \%$ other psychiatric disorders) and $15 \%$ were followed by a psychiatrist for an unknown disease. Among them, cyamemazine was the most delivered antipsychotic (30\%), followed by risperidone (25\%) and olanzapine (18\%). Table 2 includes patients with a 100\% reimbursement for psychiatric disease (ALD) apart from minor diagnostic group and patients only followed by psychiatrist. Schizophrenia, other psychoses and personality disorders were the three main diagnosed psychiatric diseases. Patients suffering from schizophrenia used more second-generation antipsychotic (70\%) mainly risperidone, anticholinergics (42\%) and depot injection (32\%) than in another group of psychiatric diseases. Tiapride which does not have schizophrenia indication was used by $1 \%$ of these patients. Adherence of patients with schizophrenia, measured by a cumulative mean gap ratio, was high. A third took antipsychotics that were depot injection. Patients with other psychoses were very similar to patients suffering from schizophrenia in terms of use of antipsychotics, anxiolytics and hypnotics while risperidone, olanzapine and aripiprazole do not have psychoses indication (other than schizophrenia). Patients with personality disorders had the same pattern of use than patients with bipolar disorders but used more first-generation antipsychotics (62\%) and less lithium (4\%) than patients with bipolar disorders (44\% and 32\%, respectively). No antipsychotic has an indication for personality disorders. Patients with alcohol abuse comprised $17 \%$ of tiapride use (one antipsychotic to have such indication). Patients with pervasive developmental disorders had fewer cotherapies than others groups: $43 \%$ had an anxiolytic, $19 \%$ an antidepressant and $2 \%$ a hypnotic. For all groups, general practitioners were the main prescribers of antipsychotics, except for the group followed by a psychiatrist.

\subsection{Patients without an ALD for Long-Term Psychiatric Disorder and without Psychiatric Follow-Up}

Patients aged between 15 and 65 years old without mental disorders accounted for $23 \%$ of the population using antipsychotics. Among them, 63\% had a FGAP (mainly cyamemazine) and $45 \%$ had more than three refunds (Table 3). The use of antipsychotics was similar to the patients aged 65 years old without dementia. Associated treatment included anxiolytics ( $59 \%$ of patients), antidepressants ( $48 \%$ of patients) and hypnotics ( $30 \%$ of patients).

Table 1. Distribution of the patients according to the antipsychotic deliverd (\% of total population).

\begin{tabular}{|c|c|c|c|c|c|}
\hline \multicolumn{3}{|c|}{ FGAPs } & \multicolumn{3}{|c|}{ SGAPs } \\
\hline Drug & $\mathrm{n}$ & $\%$ & Drug & $\mathrm{n}$ & $\%$ \\
\hline Cyamemazine & 3167 & 27.0 & Risperidone & 2647 & 22.6 \\
\hline Haloperidol & 1236 & 10.5 & Olanzapine & 1602 & 13.7 \\
\hline Sulpiride & 969 & 8.3 & Tiapride & 1088 & 9.3 \\
\hline Levomepromazine & 586 & 5.0 & Aripiprazole & 1009 & 8.6 \\
\hline Loxapine & 563 & 4.8 & Amisulpride & 769 & 6.6 \\
\hline Chlorpromazine & 245 & 2.1 & Clozapine & 173 & 1.5 \\
\hline Zuclopenthixol & 233 & 2.0 & & & \\
\hline Pipamperone & 233 & 2.0 & & & \\
\hline Periciazine & 171 & 1.5 & & & \\
\hline Fluphenazine & 132 & 1.1 & & & \\
\hline Pipothiazine & 94 & 0.8 & & & \\
\hline Flupenthixol & 80 & 0.7 & & & \\
\hline Pimozide & 71 & 0.6 & & & \\
\hline Carpipramine & 51 & 0.4 & & & \\
\hline
\end{tabular}

FGAPs: first-generation antipsychotics; SGAPs: second-generation antipsychotics, percentage by antipsychotics sums to more than $100 \%$ because patients can have more than one antipsychotics. 
Table 2. Antipsychotics characteristics of use during follow-up, by main psychiatric illnesss in patients with an "affection de longue durée" for psychiatric disease or follow by psychiatric for unknown disease. Number (percentage) or mean (SD).

\begin{tabular}{|c|c|c|c|c|c|c|c|c|}
\hline & $\begin{array}{l}\text { Schizophrenia } \\
\quad(n=1229)\end{array}$ & $\begin{array}{l}\text { Bipolar } \\
\text { disorder } \\
(n=649)\end{array}$ & $\begin{array}{l}\text { Anxiety } \\
\text { disorder } \\
(n=162)\end{array}$ & $\begin{array}{c}\text { Depression } \\
(n=671)\end{array}$ & $\begin{array}{l}\text { Other } \\
\text { psychoses } \\
(n=1011)\end{array}$ & $\begin{array}{l}\text { Personality } \\
\text { disorders } \\
(n=888)\end{array}$ & $\begin{array}{l}\text { Mental } \\
\text { retardation } \\
(n=327)\end{array}$ & $\begin{array}{c}\text { Follow by } \\
\text { psychiatrist }^{\mathrm{a}} \\
(n=1675)\end{array}$ \\
\hline FGAPs & $741(60)$ & $284(44)$ & $106(65)$ & $411(61)$ & $614(61)$ & $554(62)$ & $230(70)$ & $817(49)$ \\
\hline Cyamemazine & 336 (27) & $162(25)$ & $59(36)$ & 264 (39) & 257 (25) & 299 (33) & $102(31)$ & $446(27)$ \\
\hline Haloperidol & $258(21)$ & $58(9)$ & $16(10)$ & $32(5)$ & $206(20)$ & $82(9)$ & $38(12)$ & $101(6)$ \\
\hline Sulpiride & $12(1)$ & $13(2)$ & $15(9)$ & $54(8)$ & $11(1)$ & $34(4)$ & $6(2)$ & $109(7)$ \\
\hline SGAPs & $863(70)$ & 383 (59) & $87(54)$ & 367 (55) & 657 (65) & $512(58)$ & $175(54)$ & $1019(61)$ \\
\hline Risperidone & 353 (29) & $107(16)$ & $23(14)$ & $120(18)$ & $272(27)$ & 207 (23) & $96(26)$ & $345(21)$ \\
\hline Olanzapine & $272(22)$ & $162(25)$ & $28(17)$ & $113(17)$ & $205(20)$ & 134 (15) & $33(10)$ & $296(18)$ \\
\hline Tiapride & $18(1)$ & $20(3)$ & $13(8)$ & $38(6)$ & $36(4)$ & $54(6)$ & $30(9)$ & $148(9)$ \\
\hline Aripiprazole & $172(14)$ & $112(17)$ & $17(10)$ & $105(16)$ & $144(14)$ & $112(13)$ & $12(4)$ & $187(11)$ \\
\hline Amisulpride & $126(10)$ & $51(8)$ & $17(10)$ & $49(7)$ & $108(11)$ & $63(7)$ & $14(4)$ & $158(9)$ \\
\hline Any depot injection & 399 (32) & 39 (6) & $6(4)$ & $18(3)$ & $240(24)$ & $91(10)$ & $38(12)$ & $30(2)$ \\
\hline $\begin{array}{c}\text { Cumulative mean gap } \\
\text { ratio } \%(s d)\end{array}$ & $9.0(16.7)$ & $13.7(19.0)$ & $13.4(18.8)$ & $15.2(20.0)$ & $12.7(19.8)$ & $13.6(19.3)$ & $14.4(20.5)$ & $15.8(20.7)$ \\
\hline Anticholinergic use $\mathrm{c}^{\mathrm{c}}$ & $515(42)$ & $112(17)$ & $24(15)$ & $75(11)$ & 352 (35) & $181(20)$ & $111(34)$ & $131(8)$ \\
\hline
\end{tabular}

${ }^{\mathrm{a}}$ At least one visit to a community psychiatrist and without “Affection de longue durée” for psychiatric disease; ${ }^{\mathrm{b}}$ Cumulative Mean Gap Ratio = Total days of treatments gaps/Total days to next fill or end of observational period; 'At least one refund.

Table 3. Antipsychotic characteristics of use during follow-up in patients without an ALD for long-term psychiatric disorder and not followed by psychiatrist (\%).

\begin{tabular}{|c|c|c|c|}
\hline & \multirow{2}{*}{$\begin{array}{c}15-65 \text { years } \\
(n=2720)\end{array}$} & \multicolumn{2}{|c|}{65 years and over } \\
\hline & & No dementia $(n=1643)$ & Dementia $(n=728)$ \\
\hline No AP (sd) & $1.2(0.5)$ & $1.1(0.3)$ & $1.2(0.4)$ \\
\hline FGAPs & $1719(63)$ & $978(60)$ & 285 (39) \\
\hline Cyamemazine & $852(31)$ & $280(17)$ & $89(12)$ \\
\hline Haloperidol & $179(7)$ & $201(12)$ & $95(13)$ \\
\hline Sulpiride & $383(14)$ & 289 (18) & $38(5)$ \\
\hline SGAPs & $1220(45)$ & 707 (43) & $512(70)$ \\
\hline Risperidone & 402 (15) & $343(21)$ & $306(42)$ \\
\hline Olanzapine & $295(11)$ & $76(5)$ & 39 (5) \\
\hline Tiapride & $282(10)$ & 247 (15) & $186(26)$ \\
\hline Aripriprazole & $165(6)$ & $15(1)$ & $3(0)$ \\
\hline Amisulpride & $153(6)$ & $44(3)$ & $9(1)$ \\
\hline Lithium & $72(3)$ & $46(3)$ & $6(1)$ \\
\hline Any depot injection & $111(4)$ & $31(2)$ & $8(1)$ \\
\hline \multicolumn{4}{|l|}{ Antipsychotic use } \\
\hline One refund & 1009 (37) & $541(33)$ & $185(25)$ \\
\hline$>$ Three refunds & $1219(45)$ & 775 (47) & 385 (53) \\
\hline Anxiolytic use $\mathrm{e}^{\mathrm{a}}$ & $1598(59)$ & 897 (55) & $452(62)$ \\
\hline Antidepressant use ${ }^{\mathrm{a}}$ & $1319(48)$ & $775(47)$ & 394 (54) \\
\hline Hypnotic use $^{\mathrm{a}}$ & $823(30)$ & $514(31)$ & $221(30)$ \\
\hline Anticholinergic use $^{\mathrm{a}}$ & $245(9)$ & $95(6)$ & $26(4)$ \\
\hline
\end{tabular}

${ }^{\mathrm{a}}$ At least one refund.

$31 \%$ of those aged 65 years and over group suffered from dementia (with $9 \%$ of the whole population). $67 \%$ had more than a refund of antipsychotics during the year and $47 \%$ more than 3 (Table 3 ). The main antipsychotics used were risperidone (21\%), sulpiride (18\%), cyamemazine (17\%) and tiapride (15\%). Patients with dementia 
used more second-generation antipsychotics but less first-generation antipsychotics than patients without dementia (70\% vs. $43 \%$ and $39 \%$ vs. $60 \%$, respectively).

\section{Discussion}

In this study, we examined the patterns of use of antipsychotics in France, we found that 2.23\% of French health insurance beneficiaries had at least one reimbursement for an antipsychotic medication in 2010. An high number of patients received it without an ALD for long-term psychiatric disorder and without a follow-up by a psychiatrist. Near half of them took antipsychotics chronically. These results suggest overuse and misuse in patients without psychiatric disease.

The data obtained from the present observational study based on the EGB data are representative of the French population [8]. However, this database did not include public hospitalization in psychiatry and diagnoses were not confirmed. We used ALD, medical interventions and prescribed medicines as proxies for the assessment of diagnoses. Another limitation of this study is that it is based on information given by the French National Insurance Healthcare System (all prescription for which the patient went to the pharmacy are registered in the database), so, we have no idea if the subject really took his treatment nor are we sure whether long the treatment actually lasted.

Data concerning the patterns of use of antipsychotic are rare in France [11] [12]. Antipsychotics were prescribed to $0.7 \%$ of the population covered by the general health fund between 1990 and 1994, while 2.7\% used them during the year 2000 [11]. This was close to the $2.23 \%$ observed in 2010 and similar to the $2.4 \%$ reported in 2005 in Norway [13]. The overall level of antipsychotics reimbursement was stable in France while it increased in the United States, for example [14]. We could estimate that 1,418,019 subjects were exposed to these drugs whereas 600,000 to $1,000,000$ is an estimation of the target population according to the French Health Authority and their marketing authorization in France [15]. Even if we cannot exclude that some subjects were misclassified, the majority of subjects took at least one antipsychotic for another indication.

This study found that FGAPs and SGAPs have the same level of use in 2010. Among the FGAs, cyamemazine and haloperidol was the most commonly prescribed medication whereas risperidone and olanzapine were the most SGAs prescribed. The same results were found in a French study conducted among outpatients from 1998 to 2008 [14]. Cyamemazine is used in France for the treatment of severe anxiety in general, especially in non-psychotic patients, especially when the latter is not available to the effect of benzodiazepines. Inappropriate instructions for use affect $20 \%$ of patients under this drug. Moreover, due to anticholinergic properties, cyamemazine is considered inappropriate in the elderly [16], yet 20\% of patients that use it were aged 65 or more in our study. There were $41 \%$ of patients taking haloperidol using anticholinergic medication. Haloperidol was responsible for the more extrapyramidal side effects [2]. However, during antipsychotic treatment, the administration of anticholinergics treatment is a controversial issue. As a rule, these compounds should be used only when parkinsonism has actually developed, and when other measures, such as the reduction of antipsychotic dosage or the substitution of the administered drug by another one less prone to induce parkinsonism, were proven ineffective [17] [18]. Indeed, anticholinergics have side effects on cognitive functions, the digestive system and salivary glands [19].

In the present study, 59\% of subjects received an antipsychotic without an ALD for long-term psychiatric disorder. This rate was comparable to $58 \%$ of individuals given antipsychotic medication without any diagnosis of schizophrenia or bipolar disorder in the USA [20] and 61\% of subjects who used antipsychotics had no psychiatric disorder in Taiwan [21]. However, 15\% were followed by psychiatrists for an unknown disease which may be considered as appropriate to reduce the rate of off-label use in our study. Such use without ALD for long term psychiatric disorder could also be due to an underdiagnosis of mental disorders [22]. Finally, antipsychotic uses have been described for non-psychiatric disorders like disease of the digestive system due to anti-emetic effects but also in other mental disorder likes personality disorders or mental retardation, outside the regulatory framework [5].

Individuals between 15 and 65 years of age without an ALD for long-term psychiatric disorder and without a followed-up by a psychiatrist represented $23 \%$ of the individuals given an antipsychotic. Sixty three percent of them took FGAP that are also indicated in France, for anxiety or depression. A study on antispychotic prescriptions in UK primary care found that common diagnoses in patients without psychosis/bipolar disorder were anxiety, depression and sleep disorders [23]. It may be that clinicians quite frequently add antipsychotics due to 
their general reputation as tranquillising medications. In this case, antipsychotics are indicated for a short duration but nearly 40 percent of patients have repeated refund suggesting long term treatment (assuming that a dispensed package corresponded to a monthly prescription). Evaluation is urgently needed for that use of antipsychotics that must be seen as their primary indication.

At least $4 \%$ of patients aged from 65 years or older were exposed to antipsychotic treatment. This consumption of antipsychotics in seniors in France is actually similar to that observed in 2000 (3.4\% of men and 5.4\% of women between 70 and 79 years old) [11] even if regulatory agencies have provided warnings in March 2004 and in December 2008 about these prescriptions. The use of antipsychotics is debatable in cases of dementia among seniors due to limited efficacy and a risk of death and stroke [3] [24] [25]. There were 9\% of our antipsychotic treated population that have dementia while they represent $5.7 \%$ in USA and $4.3 \%$ in Taiwan. Besides, antipsychotics were taken on a long term basis in seniors (near $70 \%$ had more than one refund, near $50 \%$ more than 3 refunds) while they should be used for the shortest possible time in dementia [1]. Since a systemic risk assessment of cerebrovascular events, neurological and metabolic is not fully managed as expected in seniors [26], such overuse is particularly worrying in such a population. Similar misuse and overuse have been observed with benzodiazepines [27] and antidepressants [28] treatment suggesting that any regulatory action on the use of one of these drugs may have a detrimental impact on the use of the others.

\section{Conclusion}

Antipsychotic consumption remained stable over time in France. Nevertheless, this treatment was largely used particularly at long term in patient without declared psychiatric disease and without psychiatric follow-up suggesting a misuse since label of these drugs allows in France long term treatment only in ALD listed psychiatric diseases. Regarding the risk profile of these drugs, the individual benefit risk balance should be considered with caution in these patients.

\section{References}

[1] Haute Autorité de Santé (2012) Recommandation de Bonne Pratique-Maladie d'Alzheimer et Maladies Apparentées: Prise en charge des troubles du comportement perturbateurs 2009.

http://www.has-sante.fr/portail/jcms/c_819667/maladie-d-alzheimer-et-maladies-apparentees-prise-en-charge-des-trou bles-du-comportement-perturbateurs

[2] Leucht, S., Cipriani, A., Spineli, L., Mavridis, D., Örey, D., Richter, F., et al. (2013) Comparative Efficacy and Tolerability of 15 Antipsychotic Drugs in Schizophrenia: A Multiple-Treatments Meta-Analysis. The Lancet, 382, 951-962. http://dx.doi.org/10.1016/S0140-6736(13)60733-3

[3] Schneider, L.S., Dagerman, K.S. and Insel, P. (2005) Risk of Death with Atypical Antipsychotic Drug Treatment for Dementia: Meta-Analysis of Randomized Placebo-Controlled Trials. JAMA, 294, 1934-1943. http://dx.doi.org/10.1001/jama.294.15.1934

[4] Verdoux, H., Tournier, M. and Bégaud, B. (2010) Antipsychotic Prescribing Trends: A Review of Pharmaco-Epidemiological Studies. Acta Psychiatrica Scandinavica, 121, 4-10. http://dx.doi.org/10.1111/j.1600-0447.2009.01425.x

[5] Maher, A., Maglione, M., Bagley, S., et al. (2011) Efficacy and Comparative Effectiveness of Atypical Antipsychotic Medications for Off-Label Uses in Adults: A Systematic Review and Meta-Analysis. JAMA, 306, 1359-1369. http://dx.doi.org/10.1001/jama.2011.1360

[6] Alexander, G.C., Gallagher, S.A., Mascola, A., Moloney, R.M. and Stafford, R.S. (2011) Increasing Off-Label Use of Antipsychotic Medications in the United States, 1995-2008. Pharmacoepidemiology and Drug Safety, 20, 177-184. http://dx.doi.org/10.1002/pds.2082

[7] Puyat, J.H., Law, M.R., Wong, S.T., Sutherland, J.M. and Morgan, S.G. (2012) The Essential and Potentially Inappropriate Use of Antipsychotics across Income Groups: An Analysis of Linked Administrative Data. Canadian Journal of Psychiatry Revue Canadienne de Psychiatrie, 57, 488.

[8] Tuppin, P., de Roquefeuil, L., Weill, A., Ricordeau, P. and Merlière, Y. (2010) French National Health Insurance Information System and the Permanent Beneficiaries Sample. Revue d'Epidémiologie et de Santé Publique, 58, $286-290$. http://dx.doi.org/10.1016/j.respe.2010.04.005

[9] European Medicines Agency and Heads of Medicines Agencies (2012) Guideline on Good Pharmacovigilance Practices (GVP) - Module VI: Management and Reporting of Adverse Reactions to Medicinal Products.

[10] Steiner, J.F. and Prochazka, A.V. (1997) The Assessment of Refill Compliance Using Pharmacy Records: Methods, Validity, and Applications. Journal of Clinical Epidemiology, 50, 105-116. 
http://dx.doi.org/10.1016/S0895-4356(96)00268-5

[11] Lecadet, J., Bidal, P., Baris, B., Vallier, N., Fender, P., Allemand, H., et al. (2003) Médicaments psychotropes: Consommation et pratiques de prescription en France métropolitaine: I-Données nationales, 2000. Revue Médicale de l'Assurance Maladie, 34, 75-84.

[12] Diatta, T., Blazejewski, S., Portier, A., Lignot, S., Quesnot, A., Moore, N., et al. (2007) Patterns and Frequency of Atypical Antipsychotic Prescribing in Psychiatric Medical Centers: A Cross-Sectional National Survey. Fundamental \& Clinical Pharmacology, 21, 371-378. http://dx.doi.org/10.1111/j.1472-8206.2007.00492.x

[13] Kjosavik, S.R., Ruths, S. and Hunskaar, S. (2009) Psychotropic Drug Use in the Norwegian General Population in 2005: Data from the Norwegian Prescription Database. Pharmacoepidemiology and Drug Safety, 18, 572-578. http://dx.doi.org/10.1002/pds.1756

[14] Gallini, A., Donohue, J.M. and Huskamp, H.A. (2013) Diffusion of Antipsychotics in the U.S. and French Markets, 1998-2008. Psychiatric Services, 64, 680-687. http://dx.doi.org/10.1176/appi.ps.004662012

[15] Haute Autorité de Santé (2011) Avis Commission de la Transparence-XEROQUEL. http://www.has-sante.fr/portail/jcms/c_1065592/fr/xeroquel?xtmc=\&xtcr=4

[16] Laroche, M.-L., Charmes, J.-P. and Merle, L. (2007) Potentially Inappropriate Medications in the Elderly: A French Consensus Panel List. European Journal of Clinical Pharmacology, 63, 725-731. http://dx.doi.org/10.1007/s00228-007-0324-2

[17] Rathbone, J. and Soares-Weiser, K. (2006) Anticholinergics for Neuroleptic-Induced Acute Akathisia. In: The Cochrane Collaboration and Rathbone, J., Eds., Cochrane Database of Systematic Reviews, John Wiley \& Sons, Ltd., Chichester, Article No.: CD003727. http://dx.doi.org/10.1002/14651858.cd003727.pub3

[18] Soares-Weiser, K., Mobsy, C. and Holliday, E. (1997) Anticholinergic Medication for Neuroleptic-Induced Tardive Dyskinesia. In: The Cochrane Collaboration and Mobsy, C., Eds., Cochrane Database of Systematic Reviews, John Wiley \& Sons, Ltd., Chichester, Article No.: CD000204. http://dx.doi.org/10.1002/14651858.cd000204

[19] Malfoy, K., Blanchon, M.-A., Lyonnet, A. and Gonthier, R. (2008) Impact sur les fonctions cognitives des anticholinergiques prescrits chez les patients âgés de plus de 65 ans pour hyperactivité vésicale. NPG Neurologie-PsychiatrieGériatrie, 8, 6-15. http://dx.doi.org/10.1016/j.npg.2008.09.003

[20] Leslie, D.L. and Rosenheck, R. (2012) Off-Label Use of Antipsychotic Medications in Medicaid. American Journal of Managed Care, 18, e109-e117.

[21] Chien, I.-C., Hsu, J.-H., Bih, S.-H., Lin, C.-H., Chou, Y.-J., Lee, C.-H., et al. (2008) Prevalence, Correlates, and Disease Patterns of Antipsychotic Use in Taiwan. Psychiatry and Clinical Neurosciences, 62, 677-684. http://dx.doi.org/10.1111/j.1440-1819.2008.01869.x

[22] Wiechers, I.R., Leslie, D.L. and Rosenheck, R.A. (2013) Prescribing of Psychotropic Medications to Patients without a Psychiatric Diagnosis. Psychiatric Services, 64, 1243-1248. http://dx.doi.org/10.1176/appi.ps.201200557

[23] Marston, L., Nazareth, I., Petersen, I., Walters, K. and Osborn, D.P.J. (2014) Prescribing of Antipsychotics in UK Primary Care: A Cohort Study. BMJ Open, 4, e006135. http://dx.doi.org/10.1136/bmjopen-2014-006135

[24] Ballard, C. and Waite, J. (2006) The Effectiveness of Atypical Antipsychotics for the Treatment of Aggression and Psychosis in Alzheimer's Disease. Cochrane Database of Systematic Reviews, 25, Article No.: CD003476.

[25] Schneider, L.S., Dagerman, K. and Insel, P.S. (2006) Efficacy and Adverse Effects of Atypical Antipsychotics for Dementia: Meta-Analysis of Randomized, Placebo-Controlled Trials. The American Journal of Geriatric Psychiatry, 14, 191-210. http://dx.doi.org/10.1097/01.JGP.0000200589.01396.6d

[26] Arbus, C., Clement, J.-P., Bougerol, T., Fremont, P., Lancrenon, S. and Camus, V. (2012) Health Management of Older Persons with Chronically Medicated Psychotic Disorders: The Results of a Survey in France. International Psychogeriatrics, 24, 496-502. http://dx.doi.org/10.1017/S1041610211001487

[27] Fourrier, A., Letenneur, L., Dartigues, J.F., Moore, N. and Bégaud, B. (2001) Benzodiazepine Use in an Elderly Community-Dwelling Population. Characteristics of Users and Factors Associated with Subsequent Use. European Journal of Clinical Pharmacology, 57, 419-425. http://dx.doi.org/10.1007/s002280100326

[28] Percudani, M., Barbui, C., Fortino, I. and Petrovich, L. (2005) Antidepressant Drug Prescribing among Elderly Subjects: A Population-Based Study. International Journal of Geriatric Psychiatry, 20, 113-118. http://dx.doi.org/10.1002/gps.1259 


\section{Abbreviations}

ALD: Affection longue durée

ATC: Anatomical therapeutic chemical classification system

EGB: Echantillon généraliste de bénéficiaires

FGAP: First-generation antipsychotics

ICD-10: 10th version of international classification of diseases

SGAP: Second-generation antipsychotics 